\title{
High-throughput Discovery and Characterization of Multicomponent Bulk Metallic Glass Alloys
}

Peter Tsai ${ }^{a}$ \& Katharine M. Flores ${ }^{a, b}$

a. Washington University in St Louis, Institute of Materials Science \& Engineering One Brookings Drive

St Louis, MO 63130

b. Washington University in St Louis, Department of Mechanical Engineering \& Materials Science

One Brookings Drive

Campus Box 1185

St Louis, MO 63130

Primary Author: Peter Tsai ${ }^{\mathrm{a}}$

Email address: ptsai23@wustl.edu

Corresponding Author: Katharine M. Flores ${ }^{a, b}$

Email address: floresk@wustl.edu

Phone: (314) 935-3184 


\begin{abstract}
This work describes a high-throughput experimental method to characterize compositional trends in the glass forming ability and mechanical behavior of a ternary metallic alloy system. Continuously-graded composition libraries of Cu-Zr-Ti ternary alloys were produced by laser deposition, and continuous regions of glass-forming compositions were rapidly identified through an optical microscopy technique. By varying the laser processing parameters and thereby the cooling rate of the melt within each library, the composition with the greatest glass-forming ability within the range studied was determined to be $\mathrm{Cu}_{51.7} \mathrm{Zr}_{36.7} \mathrm{Ti}_{11.6}$. An alternative deposition scheme was applied to fabricate libraries containing a large array of discrete compositions. Instrumented nanoindentation was performed on the discrete libraries to establish compositional trends in the measured properties. The indentation modulus was observed to be strongly correlated with the Ti-content over the entire region of study, while the hardness was more sensitive to $\mathrm{Cu}$ for high $\mathrm{Zr}$-contents and to $\mathrm{Ti}$ at lower $\mathrm{Zr}$ contents. These trends could inform the design of new metallic glass alloys possessing an optimized balance of both ductility and glass forming ability.
\end{abstract}

\title{
1.0 Introduction
}

Over the past century, engineering alloys have become increasingly sophisticated in order to meet challenging performance specifications required by cutting-edge technology. The most advanced structural alloys of today are multicomponent, typically comprising a dominant solvent species and at least two or more minor constituents. For example, typical Ni-based superalloys used widely in the 
aerospace industry could contain more than ten alloying components to achieve complex microstructures that retain the alloys' mechanical integrity at high operating temperatures [1,2]. A promising class of multicomponent alloys, and the subject of the present study, is bulk metallic glasses (BMGs). BMGs are characterized by an amorphous atomic structure devoid of long-range translational symmetry, resulting in a rare combination of properties that are unattainable in even the most advanced crystalline alloys. These include near-theoretical strengths, large elastic strain limits, and the unique ability among metallic materials to undergo thermoplastic processing $[3,4]$. The salient commonality among these example classes of advanced engineering alloys is the vast composition space they occupy, motivating the development of combinatorial synthesis methods that could facilitate the high-throughput discovery of new alloys with optimized properties [5-9]. In this paper, we describe a novel strategy for correlating glass forming ability and other properties with composition in multicomponent BMGs.

Since the discovery of BMGs, intense focus has been directed towards understanding the origins of glass forming ability (GFA) and the necessary criteria for identifying alloy compositions with high GFA. As a result, a number of empirical rules, temperature-based metrics, and structural models have been developed for predicting optimum glass-forming compositions [10-18]. Despite the value that various guidelines and predictive parameters have contributed to the present understanding of GFA, none have demonstrated consistent reliability as standalone predictors of GFA a priori [1921]. Johnson et al. recently showed that only two parameters, the reduced glass transition temperature $\left(T_{r g}\right)$ and the dynamic fragility of the supercooled liquid, are 
necessary for quantifying GFA accurately [22]. However, these parameters are acquired from experimental measurements performed on the glass itself and consequently do not enable true predictive capability. Without a robust means of prediction, the exploration of glass formation in an alloy system still relies heavily on experimental trial and error methods.

Conventional approaches for investigating the compositional landscape of GFA in multicomponent systems typically follow a serial, one-at-a-time experimental paradigm, where discrete compositions are synthesized and their amorphous structure verified by various diffraction techniques. Despite the success of serial methods in discovering many notable BMG alloys, the sensitivity of GFA to chemical composition $[23,24]$ necessitates fabrication of an impractically large quantity of individual specimens in order to systematically probe the vast composition space occupied by multicomponent alloys. As a result, many alloy systems containing potential glass formers remain either only partially investigated or entirely unexplored.

In recent years, vapor deposition techniques have emerged as a combinatorial method to explore glass formation in complex metallic systems more efficiently [25-32]. Most notably, Ding et al. reported using magnetron co-sputtering to deposit ternary Au$\mathrm{Cu}-\mathrm{Si}$ and $\mathrm{Mg}-\mathrm{Cu}-\mathrm{Y}$ composition libraries [30,31]. By applying a thermoplastic blow molding technique to an amorphous thin-film library, the authors were able to map out the compositional landscape of thermoplastic formability and successfully identify the compositions with optimized processability. However, it is important to note that the mechanism of vitrification from the vapor phase may produce structures and glass properties that are different from glasses synthesized by liquid quenching $[33,34]$. The 
influence of the substrate in thin-film libraries may also preclude accurate determination of mechanical properties during instrumented indentation experiments.

Alternatively, we have developed a novel experimental methodology using laser additive manufacturing as a high throughput synthesis tool to accelerate the discovery of new BMGs. In our previous studies, compositionally graded specimens of the binary $\mathrm{Cu}$-Zr alloys were fabricated and the optimum glass formers within the binary system were accurately identified $[35,36]$. In the present work, we demonstrate the ability to systematically investigate GFA across the substantially larger composition space of a ternary system. Alongside this effort, we demonstrate a fabrication scheme that, when combined with instrumented nanoindentation, enables high-throughput characterization of mechanical properties across large regions in composition space.

\subsection{Experimental}

\subsection{Continuously-graded libraries for GFA optimization}

All composition libraries reported in this paper were fabricated with an Optomec MR-7 LENS ${ }^{\text {TM }}$ system. The substrates were grade 702 zirconium ground with 320 grit SiC paper and then cleaned with methanol to remove surface contaminants. The elemental powders used in the experiments had minimum purities of 99.9, 99.2, and 99.2 at. \% for $\mathrm{Cu}, \mathrm{Zr}$, and $\mathrm{Ti}$ respectively.

Three $25.4 \mathrm{~mm} \times 25.4 \mathrm{~mm}$ compositional libraries were constructed using a three layer sequential fabrication scheme with intermediate re-melting steps to fully incorporate the deposited powders. To preserve the as-deposited surface topography, the fabricated libraries were not polished following fabrication. Figure 1 provides a schematic illustration of the overall experimental concept. Each elemental powder layer 
was deposited using a constant laser power and powder delivery rate, while the travel speed of the substrate relative to the laser and powder source was varied continuously across the specimen $(8.47-29.63 \mathrm{~mm} / \mathrm{s})$ to achieve the desired composition gradient. For each library, the Zr was deposited first using a $250 \mathrm{~W}$ laser with the travel speed decreasing in the $+x$ direction (in the coordinate frame of the substrate), resulting in an increasing amount of powder deposited in the $+x$ direction. The Cu was deposited in the second layer using a $250 \mathrm{~W}$ laser with the travel speed decreasing in the $-x$ direction, in the direction opposite to the $\mathrm{Zr}$ gradient. To facilitate thorough alloying of the $\mathrm{Cu}$ and $\mathrm{Zr}$, a series of parallel, evenly spaced lines oriented in the y direction were then re-melted with a $200 \mathrm{~W}$ laser at a travel speed of $12.7 \mathrm{~mm} / \mathrm{s}$, such that each re-melted line had a fixed $\mathrm{Cu}: \mathrm{Zr}$ ratio. Ti was then deposited in the third layer, using a $150 \mathrm{~W}$ laser with the travel speed decreasing in the $+y$ direction, resulting in a Ti gradient perpendicular to the $\mathrm{Cu}-\mathrm{Zr}$ gradient. The re-melted lines were melted again to thoroughly incorporate the Ti. Thus, the Cu:Zr molar ratio nominally remained fixed within a re-melted line while the Ti content increased along the length of the line, producing a collection of tie lines in the ternary composition map. To investigate the effect of processing conditions on the compositional extent of glass formation, the final re-melting step was performed at different laser powers $(200,240$, and $280 \mathrm{~W})$ for the three libraries. An individual library required no more than 20 minutes to complete, including the three deposited layers and intermediate re-melting steps. The processing parameters used to create the specimens are summarized in Table 1.

A built-in two-wavelength pyrometer was used to obtain cooling rates at the surface of the laser melted zones corresponding to the $200 \mathrm{~W}, 240 \mathrm{~W}$, and $280 \mathrm{~W}$ laser 
power settings. In-situ acquisition of accurate temperature profiles during fabrication of

the libraries was challenging due to the varying emissivity across the libraries requiring

different camera exposure times. Because $\mathrm{Zr}$ constitutes the bulk of the thermal mass

in the composition libraries, it was assumed that cooling rates are dominated by the

thermal transport properties of the underlying substrate. Therefore, temperature profiles

were collected from laser line scans performed separately on a bare $\mathrm{Zr}$ substrate to

estimate the cooling rates involved during fabrication of the libraries.

In previous work, we have demonstrated the ability to rapidly identify glassy regions of laser-deposited composition libraries using an optical microscopy-based differential interference contrast (DIC) imaging method [35,36]. We applied this highthroughput screening method to the ternary libraries prepared in this work. As was demonstrated in our prior work, smooth, liquid-like segments were assumed to be indicative of vitrified material, in contrast to the rough surface topography of crystalline material. The correlation between the smooth surface topography and a glassy structure was later confirmed by TEM. To define a compositional range of glass formation, composition measurements were collected via energy dispersive spectroscopy (EDS) at the endpoints of each topographically-smooth segment within a library.

Following the fabrication of the continuously-graded libraries, three different alloy compositions possessing high GFA in the Cu-Zr-Ti ternary system were prepared by copper mold suction casting. Two of these alloys, $\mathrm{Cu}_{60} \mathrm{Zr}_{30} \mathrm{Ti}_{10}$ and $\left(\mathrm{Cu}_{0.64} \mathrm{Zr}_{0.36}\right)_{90} \mathrm{Ti}_{10}$, were identified in the literature as having large critical casting dimensions $[21,37]$. The third alloy, $\mathrm{Cu}_{51.7} \mathrm{Zr}_{36.7} \mathrm{Ti}_{11.6}$, was identified in the present work as potentially having a greater GFA than these literature compositions. The cast specimens were prepared 
from elemental feedstock metal with minimum purities of 99.8 at. \%. Differential scanning calorimetry (DSC) was performed for the three alloys to obtain $T_{g}$ and onset temperature of crystallization $T_{x}$. Differential thermal analysis (DTA) was used to obtain the liquidus temperature $T_{l}$. The heating rates for the DSC and DTA traces were $20 \mathrm{~K}$ $\min ^{-1}$ and $5 \mathrm{~K} \mathrm{~min}^{-1}$, respectively.

\subsection{Discrete composition library for mechanical properties evaluation}

An alternative deposition scheme was used to create a $12 \times 12$ square array of discrete composition "dot" specimens, with each dot spaced $2 \mathrm{~mm}$ from its nearest neighbors (Figure 2). $\mathrm{Cu}$ and $\mathrm{Zr}$ powders were simultaneously deposited row by row with a $250 \mathrm{~W}$ laser. In this deposition scheme, the powders were again continuously delivered to the substrate, but the laser shutter was open for a duration of 120 milliseconds only at the positions defined in the array. The delivery rates of the two elemental powders were maintained fixed during the deposition of a row of dots to achieve a constant Cu:Zr molar ratio within each row. After completion of a row, the powder delivery rates were adjusted incrementally to increase the molar ratio in the next row of dots. This was repeated sequentially until completion of the array, resulting in a discretized Cu-Zr composition gradient along each column. Following the initial deposit, a layer of Ti powder was deposited over the entire array of binary dots using a $150 \mathrm{~W}$ laser and the travel speed increasing in the $-x$ direction from $8.47-29.63 \mathrm{~mm} / \mathrm{s}$. Each dot was re-melted with a $200 \mathrm{~W}$ laser and a pulse time of 200 milliseconds to facilitate thorough mixing of the three components. In the final step, the array was re-melted again with a $180 \mathrm{~W}$ laser and reduced pulse time of 60 milliseconds. Following fabrication, EDS was used for compositional characterization of the library. 
The DIC microscopy screening method was also applied to identify vitrified dots in the discrete library. Due to the exceptionally smooth surface of the vitrified material, no further polishing was necessary to prepare the discrete dot library for instrumented nanoindentation measurements. All indentation experiments were performed with a Hysitron TI 950 Triboindenter equipped with a diamond Berkovich indenter tip. Using a maximum load of $25 \mathrm{mN}$ and loading rate of $3.1 \mathrm{mN} / \mathrm{s}$, four indents, spaced $10 \mu \mathrm{m}$ apart, were performed in the central region of each vitrified dot in the array to obtain average hardness $(H)$ and indentation modulus $\left(E_{r}\right)$ values.

\subsection{Results}

\subsection{Continuously-graded libraries}

A number of distinct surface topographies were observed in the as-deposited specimens, representing a wide spectrum of possible microstructures, from fully amorphous (featureless and smooth) to fully crystalline (rough with distinct asperities) (Figure 3). The surface roughness of smooth regions was quantitatively evaluated with scanning probe microscopy. The resulting probe images yielded sub-nanometer roughness values, an order of magnitude lower than the surface roughness of metallic samples that have been polished to a mirror finish with colloidal media.

Using the smooth surface topography as an indicator of a predominantly glassy structure, the compositional range of glass formation was identified in each of the three as-deposited libraries (Figure 4). The compositional range of the glass region was observed to diminish with increasing laser power (or laser heat input, defined below), consistent with our previous findings in the $\mathrm{Cu}-\mathrm{Zr}$ binary system $[35,36]$. A master plot containing the experimentally-obtained glass region of each library is shown on the 
ternary composition map in Figure 5. For comparison, two compositions $[21,37]$ reported in literature to possess high GFA are also shown on the plot.

Average surface cooling rates estimated from laser melting a $\mathrm{Zr}$ substrate are listed in Table 1, calculated directly from the measured thermal profiles by the product of the temperature gradient with laser travel speed, averaged from 1600 to $2200{ }^{\circ} \mathrm{C}$. (While the cooling rate through the glass transition temperature is of greatest interest, lower temperatures were not accessible by the two wavelength pyrometer employed in this study.) The estimated rates decrease with increasing laser power, in agreement with the diminishing compositional range of vitrified regions in the three continuouslygraded libraries. The magnitude of the estimated surface cooling rates are also consistent with prior finite element analyses of cooling rates achieved with the LENS ${ }^{\text {TM }}$ process $[38,39]$.

\subsection{Discrete dot composition library}

Figure 6 shows a cross-sectional view of a dot screened as amorphous in the discrete composition library. Heat affected zones corresponding to each re-melting step are clearly visible, surrounding a featureless melt zone that is presumably amorphous. The featureless melt zone has a depth of approximately $200 \mu \mathrm{m}$, sufficiently thick to avoid substrate effects during nanoindentation. The apex of the dots provided a flat, planar surface for nanoindentation, eliminating the usual requirement of post-fabrication polishing. Assuming a radius of curvature of at least $1 \mathrm{~mm}$, and indentations with lateral dimensions of $2 \mu \mathrm{m}$, the variation in surface height across the width of an indent would not exceed $10 \mathrm{~nm}$ for the indents performed in this study, meeting the acceptable surface condition required for nanoindentation. 
Of the 144 discrete dots in the discrete composition library, 92 of them were screened as amorphous via differential interference contrast imaging. Figure 7 shows property-composition contour plots for the measured $E_{r}$ and $H$ values. Each data point used to construct the plots represents the average value of interest from the four indents performed on every vitrified dot in the array (see Experimental). The average standard deviation was $0.85 \mathrm{GPa}$ and $0.03 \mathrm{GPa}$ for $E_{r}$ and $H$, respectively.

It should be noted that the discrete and continuously graded composition libraries did not overlap completely; the continuous libraries extended to larger Ti contents than the $12 \times 12$ array of discrete dots. Thus, while the property maps of Figure 7 do not include all of the glass forming compositions delineated in Figure 5, this is because the complete $12 \times 12$ array did not include any dots in that composition range. In fact, the glass forming range of the discrete dots extends to lower $\mathrm{Ti}$ and $\mathrm{Cu}$ contents than was observed in any of the continuously-graded libraries.

\subsection{Discussion}

A central goal of this work was to demonstrate a high-throughput method for evaluating glass forming ability as a function of composition in multicomponent alloys. This was facilitated by the use of differential interference contrast (DIC) optical microscopy, which is highly sensitive to surface topography, to screen the as-deposited libraries and eliminate the obviously crystalline compositions from further consideration. When the free surface of a liquid solidifies, crystal nucleation and growth produces a rough surface that is easily visible using DIC [40]. In contrast, if the liquid vitrifies on cooling, no surface asperities are apparent using DIC, suggesting a lack of crystallites larger than the resolution of the measurement, on the order of $100 \mathrm{~nm}$. Further scanning 
probe microscopy observations of the smooth regions identified by DIC confirmed subnanometer RMS surface roughness values, consistent with the lack of even smaller crystallites. Using this screening as a first step, the amorphous structure can then be confirmed by x-ray or electron diffraction methods. In our previous studies of the binary Cu-Zr system $[35,36]$, TEM foils extracted from the smooth areas identified by DIC were repeatedly verified as amorphous by electron diffraction, lending support for DIC microscopy as a reliable screening tool. For the remainder of this work, we assume that the regions of the composition libraries screened as "smooth" by DIC are primarily amorphous.

In order to evaluate the glass-forming ability of a given alloy composition, it is necessary to experimentally access a wide range of cooling rates. In the conventional serial casting approach, this is accomplished primarily by casting wedge shaped specimens or several individual specimens of different cross-sectional thicknesses, in order to determine the critical casting thickness that avoids crystallization. Notably, the measured critical thicknesses are highly sensitive to other processing parameters, such as the initial temperature of the melt or dwell time in the liquid phase prior to casting. Differences in the details of the processing often lead to different critical casting dimensions [24] as measured by different laboratories, complicating cross-lab comparisons. In the present work, the full range of compositions in a given library are prepared under consistent processing conditions, facilitating the GFA comparison.

In laser processing, cooling rates within the localized melt pool depend largely on the laser heat input, defined as $\lambda=P /(v D)$, where $P, v$, and $D$ denote laser power, travel speed, and beam diameter, respectively. It is well-known from studies involving 
crystalline alloys that high laser powers or low travel speeds produce coarser grain microstructures, signaling an inverse scaling of cooling rate with $\lambda$ [41-43]. Thus, an alloy's minimum or critical cooling rate should correspond to an upper limit of $\lambda$. Indeed, Chen et al. performed laser surface melting experiments on $\mathrm{Cu}_{60} \mathrm{Zr}_{30} \mathrm{Ti}_{10}$ substrates and reported a threshold laser power above which crystallization became unavoidable [44]. Similarly, Sun and Flores conducted laser deposition experiments with a Zr-based BMG powder on amorphous substrates of the same composition [45]. By fixing $P$ and increasing $v$ above a threshold value, the authors were able to nearly eliminate crystalline features from the heat affected zone. Taking advantage of the empirical relationship between GFA and laser heat input, we demonstrated in our prior studies of compositionally-graded binary specimens that increasing the applied $\lambda$ has the general effect of narrowing the compositional range of glass formation towards the best glassformer in the system.

It follows that the reduction in the extent of the smooth region within the ternary composition libraries with increasing laser power, or equivalently, increasing $\lambda$ (Figure 5), was a direct consequence of subjecting the ternary libraries to successively lower cooling rates. Our pyrometer measurements of surface temperature profiles indicated that increasing the laser power from $200 \mathrm{~W}$ to $280 \mathrm{~W}$ reduces the average cooling rate by nearly $30 \%$. As cooling rates decreased with increasing laser power, fewer compositions remained that could vitrify, resulting in the gradual convergence of the glass region towards the composition with the highest GFA. Based on this trend in GFA with $\lambda$ and a qualitative assessment of the overlapping regions in Figure 5, GFA appears to be much more sensitive to the Ti content than to $\mathrm{Cu}$ or $\mathrm{Zr}$; the glass forming 
regions narrow much more rapidly with changes in $\mathrm{Ti}$ content than with $\mathrm{Cu}$ or $\mathrm{Zr}$. This is consistent with the extensive glass forming range of the $\mathrm{Cu}$-Zr binary system.

It is important to note that the average surface cooling rates (on the order of $10^{4}$ $\mathrm{K} / \mathrm{s}$ ) measured with the pyrometer are not the critical cooling rates required for glass formation in the vitrified regions within the libraries. The critical cooling rate for glass formation is derived from averaging the instantaneous cooling rate in the temperature range between $T_{g}$ and $T_{l}$, approximately $430-900{ }^{\circ} \mathrm{C}$ for near-eutectic $\mathrm{Cu}-\mathrm{Zr}-\mathrm{Ti}$ compositions, well below the range of the pyrometer employed in the present study. However, the measured surface cooling rates are consistent with the results of previous finite element models of laser surface melting in similar metallic glass systems [38,39]. These models demonstrated that the instantaneous cooling rate decreases rapidly with time and temperature after the surface heating event. Approaching the glass transition temperature, the cooling rates measured by the models were an order of magnitude lower than those measured at high temperatures. Both the peak temperature and the cooling rates also decrease rapidly away from the surface. While the high temperature surface cooling rates measured here represent an extreme, the pyrometry results remain useful in providing quantitative verification of the inverse relationship between laser heat input and average cooling rate, as well as the relative change in the necessary critical cooling rate for extending the compositional region of glass formation.

Based on the observed GFA trend with composition, we predicted $\mathrm{Cu}_{51.7} \mathrm{Zr}_{36.7} \mathrm{Ti}_{11.6}$ as the optimum glass former in the region of the ternary system covered by our composition libraries. Within this ternary system, Inoue et al. had previously identified $\mathrm{Cu}_{60} \mathrm{Zr}_{30} \mathrm{Ti}_{10}$ as a notable glass former [21], while Wang et al. 
further explored glass formation along a series of compositional tie lines and reported $\left(\mathrm{Cu}_{0.64} \mathrm{Zr}_{0.36}\right)_{90} \mathrm{Ti}_{10}$ as the best glass former in the alloy system [37]. (Note the similarity in the Ti content among these three "optimal" compositions, which again highlights the strong sensitivity of GFA to $\mathrm{Ti}$ in this system.) Both studies reported a critical rod diameter of $4 \mathrm{~mm}$ for their respective compositions. It is significant that while these two compositions occupied the vitrified region of the $200 \mathrm{~W}$ library, they were excluded from the glass regions in the 240 and $280 \mathrm{~W}$ libraries, implying that our predicted composition should exhibit higher GFA. In addition, although the same reported critical casting diameter of the Inoue and Wang compositions would suggest equivalence of GFA, our results indicated that $\mathrm{Cu}_{60} \mathrm{Zr}_{30} \mathrm{Ti}_{10}$, positioned near the periphery of the vitrified region in the $200 \mathrm{~W}$ library, should have poorer glass forming ability than both Wang's alloy and our predicted composition.

To validate our method for optimizing GFA, wedge samples of $\mathrm{Cu}_{51.7} \mathrm{Zr}_{36.7} \mathrm{Ti}_{11.6}$, $\mathrm{Cu}_{60} \mathrm{Zr}_{30} \mathrm{Ti}_{10}$, and $\left(\mathrm{Cu}_{0.64} \mathrm{Zr}_{0.36}\right)_{90} \mathrm{Ti}_{10}$ were prepared by copper mold suction casting. Care was taken to maintain consistent processing conditions for all three alloys. The wedge critical casting thickness was determined to be $1.50,1.35$, and $1.20 \mathrm{~mm}( \pm 0.05$ $\mathrm{mm}$ ), respectively for $\mathrm{Cu}_{51.7} \mathrm{Zr}_{36.7} \mathrm{Ti}_{11.6},\left(\mathrm{Cu}_{0.64} \mathrm{Zr}_{0.36}\right)_{90} \mathrm{Ti}_{10}$, and $\mathrm{Cu}_{60} \mathrm{Zr}_{30} \mathrm{Ti}_{10}$. While these differences are small, they are consistent with the expected ranking of GFA among the three alloys based on the results from the laser-deposited libraries. The apparent discrepancy between the critical casting dimensions measured here and those measured by the Inoue and Wang studies again highlights the difficulty of comparing critical casting dimensions across multiple laboratories and processing methods to evaluate GFA. 
Figure 8 provides the DSC heating traces for the three suction cast samples. The glass transition temperature $T_{g}$, crystallization temperature $T_{x}$, and liquidus temperature $T_{I}$ (obtained from DTA measurements) for each alloy are listed in Table 2. Also listed are $T_{r g}=T_{g} / T_{1}$ and $\Delta T=\left(T_{x}-T_{g}\right)$, two of the most prevalent indicators of GFA and glass stability in the literature. According to the ranking of $\Delta T, \mathrm{Cu}_{51.7} \mathrm{Zr}_{36.7} \mathrm{Ti}_{11.6}$ has the lowest thermal stability, defined here as the temperature range over which the supercooled liquid resists crystallization. On the other hand, the similar $T_{r g}$ values show no correlation with the respective glass forming ability of the three alloys, as measured by either their critical casting thicknesses or their assumed critical laser heat inputs based on the present work. This demonstrates that, although temperature-based predictors reflect certain crucial aspects of glass formation, they neglect other important determining factors of GFA, such as the structural motifs that comprise the overall glass as well as kinetic properties (e.g. viscosity, dynamic fragility) of the supercooled liquid.

A second major objective of this work was to identify correlations between glass composition and mechanical behavior, taking advantage of the extensive compositional range that can be rapidly produced by the laser deposition technique. The contour plot (Figure 7a) of the measured indentation modulus values from the discrete library shows a strong inverse relationship between $E_{r}$ and the titanium content and less sensitivity of $E_{r}$ to changes in the $\mathrm{Cu}: \mathrm{Zr}$ molar ratio. It is as yet unclear if and how the sensitivity of GFA to the $\mathrm{Ti}$ content (and relative insensitivity to $\mathrm{Cu}$ and $\mathrm{Zr}$ ) is related to the dependence of $E_{r}$ on $\mathrm{Ti}$, although the elastic modulus depends on atomic bonding characteristics and hence the degree of local ordering, which should in turn influence 
glass formation. It is apparent that glass formation does not directly correlate with the elastic modulus.

For alloys with $\mathrm{Zr}$ contents less than $\sim 37$ at. \%, the hardness also exhibits an inverse relationship with the Ti content (Figure 7b). However, for alloys with greater than 37 at $\% \mathrm{Zr}, H$ instead scales with the $\mathrm{Cu}$ content. Again, there is no clear correlation between the hardness and GFA. However, it is interesting that the optimal glass forming composition identified in this work, $\mathrm{Cu}_{51.7} \mathrm{Zr}_{36.7} \mathrm{Ti}_{11.6}$ (marked with a red $\mathrm{X}$ in Figure $7 \mathrm{~b}$ ), is on the boundary between the region where $\mathrm{H}$ scales with $\mathrm{Cu}$ and where it scales with Ti. Like the elastic modulus, the hardness (or resistance to plastic deformation) should depend on the underlying atomic structure, in particular the ease with which atomic rearrangements occur. That our optimal composition occurs along the intersection of two competing compositional trends in hardness suggests that it may correspond to a composition where two structural motifs are competing for dominance. Further study is required to describe the glass structure as a function of composition in this region of the ternary system.

The disparate compositional trends of $H$ and $E_{r}$ over the majority of the investigated compositions contrasts with a previous study investigating the correlation between Vickers hardness and shear modulus for a wide variety of BMGs belonging to different compositional families [46]. In that work, the hardness was observed to scale linearly with shear modulus. Figure $7 \mathrm{c}$ shows a master plot of $H$ versus $E_{r}$ from data obtained in the present study. The data exhibits a large amount of scatter; a linear fit to the data yielded a relatively low $R^{2}$ value of 0.42 . However, within narrow bands of $\mathrm{Cu}: Z r$ ratios (highlighted by the color-coded scale provided), a stronger linear trend 
does seem to persist, with higher $\mathrm{Cu}: \mathrm{Zr}$ ratios yielding larger intercept values for the trend lines (not shown). Although these results suggest a weak correlation between hardness and modulus over the entire composition range, it is important to recognize that our measurements were limited to only ternary $\mathrm{Cu}-\mathrm{Zr}$ - $\mathrm{Ti}$ alloys and covered a relatively narrow range of hardness values. From a global perspective that includes all BMG alloys, a strong linear relationship between hardness and modulus may still apply, but here we show that deviation from the rule is possible when studying a specific family of alloys.

As shown in Figure 7c, for a given value of indentation modulus, hardness increases with increasing $\mathrm{Cu}$ content. Indentation hardness measures the resistance of a material to permanent deformation under a constrained state of stress determined by the indenter shape, the applied load, and the material's elastic properties. For two compositions possessing identical $E_{r}$ but different $H$ values, the elastic contribution to the total tip displacement is the same for both alloys, but the plastic contribution is larger for the alloy with the lower hardness. That is, the alloy with the lower $H$ value would be intrinsically less resistant against plastic flow under identical loading conditions. The direct implication of the trend in hardness with $\mathrm{Cu}: \mathrm{Zr}$ ratio for a fixed $E_{r}$ value is that reducing the overall $\mathrm{Cu}$ content in the ternary alloys may enhance plasticity.

Recent molecular dynamics studies of the binary $\mathrm{Cu}-\mathrm{Zr}$ system carried out by $\mathrm{Ma}$ et al. have linked elastically soft regions within the heterogeneous structure of the model glasses to a propensity to undergo localized, non-affine shear transformations $[47,48]$. Moreover, the soft regions strongly corresponded with the most unstable atomic cluster species, termed by the authors as geometrically unstable motifs (GUMs). It was 
observed that the population of GUMs increased with increasing $\mathrm{Zr}$ content (decreasing $\mathrm{Cu}$ ) in the binary alloys, providing a fundamental design rationale for the discovery of $\mathrm{Zr}_{61} \mathrm{Cu}_{25} \mathrm{Al}_{12} \mathrm{Ti}_{2}$, which to date exhibits the highest reported fracture toughness among known monolithic BMG alloys [49]. Our experimental finding that decreasing the $\mathrm{Cu}$ content promotes plastic deformation in Cu-Zr-Ti ternary alloys is in agreement with the results of these previous studies, suggesting structural changes of the glass with varying composition as the underlying reason for the measured trends in $H$ and $E_{r}$.

The present work introduces a high-throughput method for rapidly evaluating the relative ductility or toughness of glass forming alloys. It should be noted that the state of stress in nanoindentation experiments is very different from the stress distribution immediately ahead of crack tip in fracture toughness tests, and one could argue that pronounced plasticity observed in indentation does not necessarily translate to higher fracture toughness or ductility. However, if we assume that plastic flow is ultimately dictated by the availability of structurally soft regions that are more susceptible to shear transformation, alloys with a denser population of soft spots should display a greater intrinsic capacity for accommodating plastic strain regardless of the manner in which stress is applied. Although further experimental validation is needed, we propose that the high-throughput mechanical testing method described in this paper, in conjunction with computational modeling, offers a promising pathway for designing new monolithic alloys with optimal combinations of toughness and GFA.

\subsection{Conclusions}

We have demonstrated a novel high-throughput methodology to systematically examine glass formation in complex, multicomponent alloy systems. Continuously 
graded Cu-Zr-Ti libraries covering a composition range of several tens of atomic percent were rapidly fabricated by a laser additive manufacturing technique. Smooth, liquid-like surface topographies in the as-deposited libraries were indicative of vitrified material, enabling rapid screening via optical microscopy to define continuous regions of glass forming within a library. Multiple libraries were synthesized with varying laser heat input in the final re-melting step. With increasing laser heat input, the regions of glass formation were observed to gradually diminish towards the glass-forming composition(s) with the lowest critical cooling rate(s). $\mathrm{Cu}_{51.7} \mathrm{Zr}_{36.7} \mathrm{Ti}_{11.6}$ was estimated as the optimum glass former in the ternary system and subsequent casting results verified the new alloy's superior GFA in comparison with previously identified bulk glass formers.

Nanoindentation measurements performed on the discrete composition library revealed that indentation modulus was primarily sensitive to the $\mathrm{Ti}$ content, while hardness was sensitive to $\mathrm{Ti}$ for low $\mathrm{Zr}$ contents and to $\mathrm{Cu}$ for high $\mathrm{Zr}$ contents. The cross-over in the trend for hardness with composition, which corresponded to the composition of the optimal glass former identified in this work, suggested a change in the underlying structural motifs controlling both glass forming ability and plastic deformation. Comparison of the hardness and modulus trends further suggested that reducing the $\mathrm{Cu}$ content promotes ductility.

Although the procedural strategy described in this study is most suitable for exploring ternary composition space, it could be adapted to interrogate higher order systems through the use of elemental powder blends and pre-alloyed powders. An alternative application of our methodology is the optimization of existing multicomponent BMGs that possess notably high GFA. It is unclear whether such BMGs, originally 
identified through conventional serial casting methods, truly represent the global GFA maxima in their respective composition space. However, it is likely that the global maximum lies in the compositional neighborhood of these alloys [24]. By using the method described in this paper to probe the neighboring space surrounding known glass formers, new BMGs with optimized GFA could be quickly identified.

\subsection{Acknowledgements}

This work was funded by the Defense Threat Reduction Agency, award number HDTRA1-11-1-0047. P.T. was partially supported by the Saigh Fund at Washington University. Copper powder was provided by the Materials Preparation Center, Ames Laboratory, US DOE Basic Energy Sciences, Ames, IA, USA.

\subsection{References}

[1] P. Caron, K. Tasadduq, Evolution of Ni-based superalloys for single crystal gas turbine blade applications, Aerosp. Sci. Technol. 3 (1999) 513-523.

[2] D. Furrer, H. Fecht, Ni-based superalloys for turbine discs, Jom. 51 (1999) 14-17.

[3] W.H. Wang, C. Dong, C.H. Shek, Bulk metallic glasses, Mater. Sci. Eng. R Reports. 44 (2004) 45-89.

[4] J. Schroers, Processing of bulk metallic glass, Adv. Mater. 22 (2010) 1566-1597.

[5] J.C. Zhao, A combinatorial approach for structural materials, Adv. Eng. Mater. 3 (2001) 143-147.

[6] J.C. Zhao, Combinatorial approaches as effective tools in the study of phase diagrams and composition-structure-property relationships, Prog. Mater. Sci. 51 (2006) 557-631.

[7] T. Gebhart, D. Music, T. Takahashi, J.M. Schneider, Combinatorial thin film materials science: From alloy discovery and optimization to alloy design, Thin Solid Films. 520 (2012) 5491-5499.

[8] S.M. Han, R. Shah, R. Banerjee, G.B. Viswanathan, B.M. Clemens, W.D. Nix, Combinatorial studies of mechanical properties of Ti-Al thin films using nanoindentation, Acta Mater. 53 (2005) 2059-2067.

[9] A. Ludwig, R. Zarnetta, S. Hamann, A. Savan, S. Thienhaus, Development of multifunctional thin films using high-throughput experimentation methods, Int. J. Mater. Res. 99 (2008) 1144-1149.

[10] D. Turnbull, Under what conditions can a glass be formed?, Contemp. Phys. 10 
(1969) 473-488.

[11] A. Inoue, T. Zhang, T. Masumoto, Glass-forming ability of alloys, J. Non. Cryst. Solids. 156-158 (1993) 473-480.

[12] A. Inoue, STABILIZATION OF METALLIC SUPERCOOLED LIQUID, Acta Mater. 48 (2000) 279-306.

[13] D.B. Miracle, A structural model for metallic glasses, Nat. Mater. 3 (2004) 697702.

[14] D.B. Miracle, The efficient cluster packing model - An atomic structural model for metallic glasses, Acta Mater. 54 (2006) 4317-4336.

[15] A.P. Wang, J.Q. Wang, E. Ma, Modified efficient cluster packing model for calculating alloy compositions with high glass forming ability, Appl. Phys. Lett. 90 (2007) 121912.

[16] Y.Q. Cheng, E. Ma, Atomic-level structure and structure-property relationship in metallic glasses, Prog. Mater. Sci. 56 (2011) 379-473.

[17] Z.P. Lu, C.T. Liu, A new glass-forming ability criterion for bulk metallic glasses, Acta Mater. 50 (2002) 3501-3512.

[18] K.J. Laws, D.B. Miracle, M. Ferry, A predictive structural model for bulk metallic glasses., Nat. Commun. 6 (2015) 8123.

[19] T.A. Waniuk, J. Schroers, W.L. Johnson, Critical cooling rate and thermal stability of $\mathrm{Zr}-\mathrm{Ti}-\mathrm{Cu}-\mathrm{Ni}-\mathrm{Be}$ alloys, Appl. Phys. Lett. 78 (2001) 1213-1215.

[20] Z. Long, G. Xie, H. Wei, X. Su, J. Peng, P. Zhang, A. Inoue, On the new criterion to assess the glass-forming ability of metallic alloys, Mater. Sci. Eng. A. 509 (2009) 23-30.

[21] A. Inoue, W. Zhang, T. Zhang, K. Kurosaka, High-strength Cu-based bulk glassy alloys in $\mathrm{Cu}-\mathrm{Zr}-\mathrm{Ti}$ and $\mathrm{Cu}-\mathrm{Hf}-\mathrm{Ti}$ ternary systems, Acta Mater. 49 (2001) 26452652.

[22] W.L. Johnson, J.H. Na, M.D. Demetriou, Quantifying the origin of metallic glass formation, Nat. Commun. 7 (2016) 10313.

[23] H. Choi-Yim, D. Xu, W.L. Johnson, Ni-based bulk metallic glass formation in the $\mathrm{Ni}-\mathrm{Nb}-\mathrm{Sn}$ and $\mathrm{Ni}-\mathrm{Nb}-\mathrm{Sn}-\mathrm{X}(\mathrm{X}=\mathrm{B}, \mathrm{Fe}, \mathrm{Cu})$ alloy systems, Appl. Phys. Lett. 82 (2003) 1030-1032.

[24] J.H. Na, M.D. Demetriou, M. Floyd, A. Hoff, G.R. Garrett, W.L. Johnson, Compositional landscape for glass formation in metal alloys., Proc. Natl. Acad. Sci. U. S. A. 111 (2014) 9031-6.

[25] Y.P. Deng, Y.F. Guan, J.D. Fowkes, S.Q. Wen, F.X. Liu, G.M. Pharr, P.K. Liaw, C.T. Liu, P.D. Rack, A combinatorial thin film sputtering approach for synthesizing and characterizing ternary ZrCuAl metallic glasses, Intermetallics. 15 (2007) 1208-1216.

[26] C.J. Chen, J.C. Huang, H.S. Chou, Y.H. Lai, L.W. Chang, X.H. Du, J.P. Chu, T.G. Nieh, On the amorphous and nanocrystalline $\mathrm{Zr}$ - $\mathrm{Cu}$ and $\mathrm{Zr}$ - Ti co-sputtered thin films, J. Alloys Compd. 483 (2009) 337-340. 
[27] H.S. Chou, J.C. Huang, Y.H. Lai, L.W. Chang, X.H. Du, J.P. Chu, T.G. Nieh, Amorphous and nanocrystalline sputtered $\mathrm{Mg}-\mathrm{Cu}$ thin films, J. Alloys Compd. 483 (2009) 341-345.

[28] S. Hata, R. Yamauchi, J. Sakurai, A. Shimokohbe, Combinatorial Arc Plasma Deposition of Thin Films, Jpn. J. Appl. Phys. 45 (2006) 2708-2713.

[29] A.Y. Li, Q. Guo, J.A. Kalb, C. V Thompson, Y. Li, Matching Glass-Forming Ability with the Density of the Amorphous Phase, Science 322 (2008) 1816-1819.

[30] S. Ding, J. Gregoire, J.J. Vlassak, J. Schroers, Solidification of Au-Cu-Si alloys investigated by a combinatorial approach, J. Appl. Phys. 111 (2012) 1-7.

[31] S. Ding, Y. Liu, Y. Li, Z. Liu, S. Sohn, F.J. Walker, J. Schroers, Combinatorial development of bulk metallic glasses, Nat. Mater. 13 (2014) 1-7.

[32] S. Evertz, J. Gamcova, J. Bednarcik, V. Schnabel, K. Mathias, D. Music, D. Raabe, J.M. Schneider, Revealing the relationships between chemistry, topology and stiffness of ultrastrong Co-based metallic glass thin films : A combinatorial approach, Acta Mater. 107 (2016) 213-219.

[33] H. Bin Yu, Y. Luo, K. Samwer, Ultrastable metallic glass, Adv. Mater. 25 (2013) 5904-5908.

[34] N. Chen, R. Frank, N. Asao, D. V. Louzguine-Luzgin, P. Sharma, J.Q. Wang, G.Q. Xie, Y. Ishikawa, N. Hatakeyama, Y.C. Lin, M. Esashi, Y. Yamamoto, A. Inoue, Formation and properties of Au-based nanograined metallic glasses, Acta Mater. 59 (2011) 6433-6440.

[35] P. Tsai, K.M. Flores, A combinatorial strategy for metallic glass design via laser deposition, Intermetallics 55 (2014) 162-166.

[36] P. Tsai, K.M. Flores, A Laser Deposition Strategy for the Efficient Identification of Glass-Forming Alloys, Metall. Mater. Trans. A. 46A (2015) 3876-3882.

[37] Q. Wang, J.B. Qiang, J.H. Xia, J. Wu, Y.M. Wang, C. Dong, Cu-Zr-Al(Ti) bulk metallic glasses: Cluster selection rules and glass formation, Intermetallics. 15 (2007) 711-715.

[38] H. Sun, K.M. Flores, Laser deposition of a Cu-based metallic glass powder on a Zr-based glass substrate, J. Mater. Res. 23 (2008) 2692-2703.

[39] H. Sun, K.M. Flores, Formation of metallic glass coatings via laser deposition, 30th Int. Congr. Appl. Lasers Electro-Optics, ICALEO 2011, Oct. 23, 2011 - Oct. 27, 2011. (2011) 503-510.

[40] D. Ausserre, M.P. Valignat, Wide-Field Optical Imaging of Surface Nanostructures, Nano Lett. 6 (2006) 1384-1388.

[41] J.D. Majumdar, a. Pinkerton, Z. Liu, I. Manna, L. Li, Microstructure characterisation and process optimization of laser assisted rapid fabrication of 316L stainless steel, Appl. Surf. Sci. 247 (2005) 320-327.

[42] T. Amine, J.W. Newkirk, F. Liou, An investigation of the effect of direct metal deposition parameters on the characteristics of the deposited layers, Case Stud. Therm. Eng. 3 (2014) 21-34. 
[43] W.E. Frazier, Metal additive manufacturing: A review, J. Mater. Eng. Perform. 23 (2014) 1917-1928.

[44] B.Q. Chen, Y. Li, Y. Cai, R. Li, S.J. Pang, T. Zhang, Surface vitrification of alloys by laser surface treatment, J. Alloys Compd. 511 (2012) 215-220.

[45] H. Sun, K.M. Flores, Microstructural Analysis of a Laser-Processed Zr-Based Bulk Metallic Glass, Metall. Mater. Trans. A. 41A (2010) 1752-1757.

[46] X.Q. Chen, H. Niu, D. Li, Y. Li, Modeling hardness of polycrystalline materials and bulk metallic glasses, Intermetallics. 19 (2011) 1275-1281.

[47] J. Ding, S. Patinet, M.L. Falk, Y. Cheng, E. Ma, Soft spots and their structural signature in a metallic glass, Proc. Natl. Acad. Sci. 111 (2014) 14052-14056.

[48] E. Ma, Tuning order in disorder, Nat. Mater. 14 (2015) 547-552.

[49] J. Xu, E. Ma, Damage-tolerant Zr-Cu-Al-based bulk metallic glasses with recordbreaking fracture toughness, J. Mater. Res. 29 (2014) 1489-1499. 

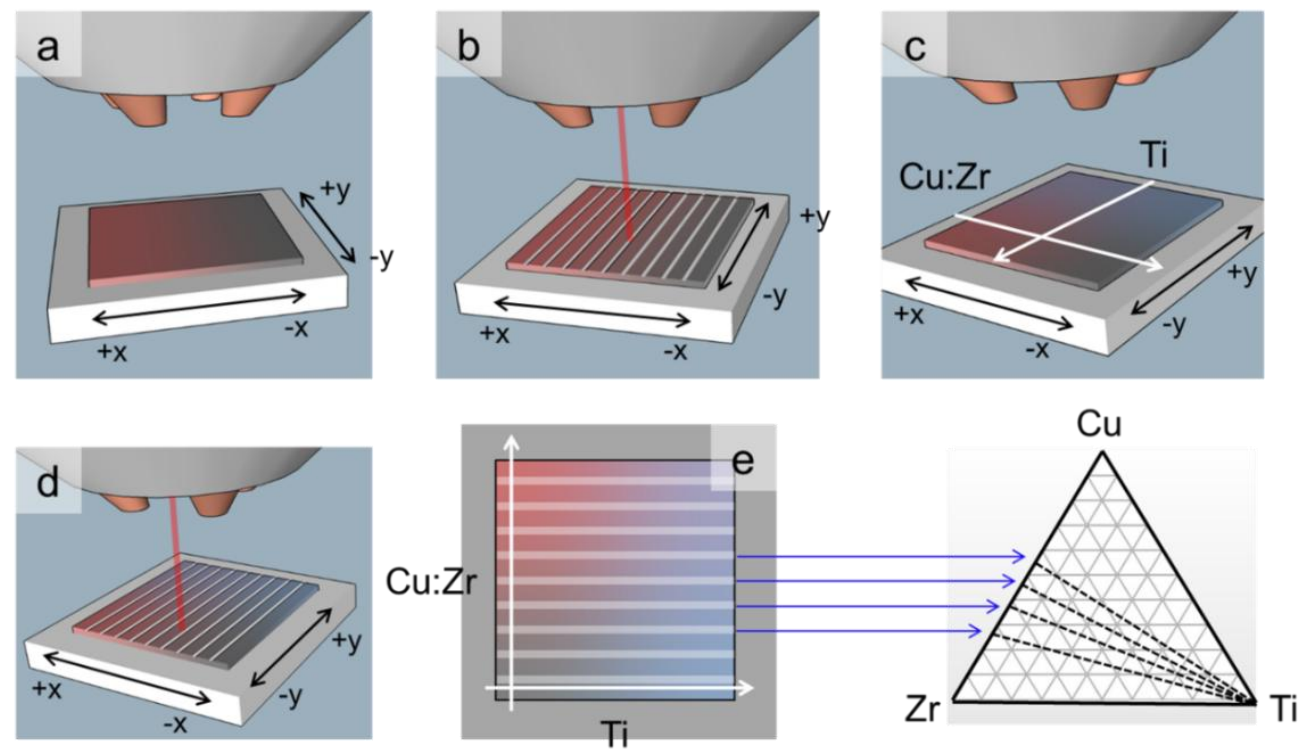

Figure 1 Experimental concept for fabricating a Cu-Zr-Ti composition library via laser additive manufacturing. a, Initial deposition of two successive layers of $\mathrm{Cu}$ and $\mathrm{Zr}$ to produce a graded $\mathrm{Cu}-\mathrm{Zr}$ composition profile. $\mathbf{b}$, Creation of evenly-spaced remelted lines perpendicular to the direction of the composition gradient to promote thorough mixing of the two components. c, Deposition of Ti gradient in a direction perpendicular to the initial gradient. $\mathbf{d}$, Final glazing of the re-melted lines with a fast laser to promote vitrification. $\mathbf{e}$, The alloyed lines in the completed library correspond to ternary tie lines featuring a fixed $\mathrm{Cu}: \mathrm{Zr}$ ratio.
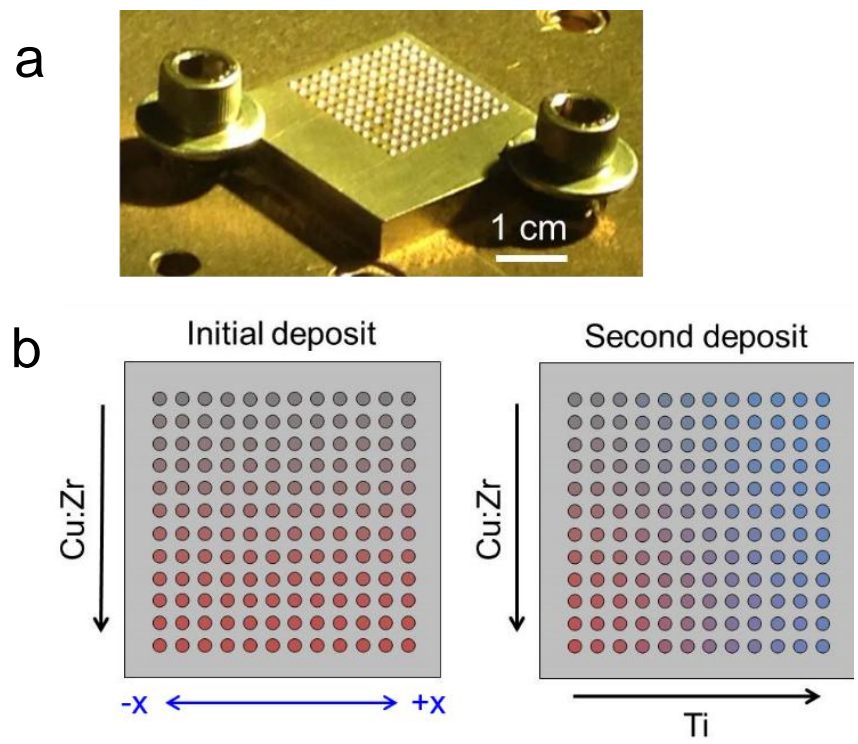

Figure 2 a, Photograph of discrete dot Cu-Zr-Ti composition library. b, Schematic illustrating the deposition scheme for incorporating the desired composition gradients in 
the discrete dot libraries. Black arrows indicate direction of increasing $\mathrm{Cu}: \mathrm{Zr}$ molar ratio (vertical) and Ti content (horizontal).

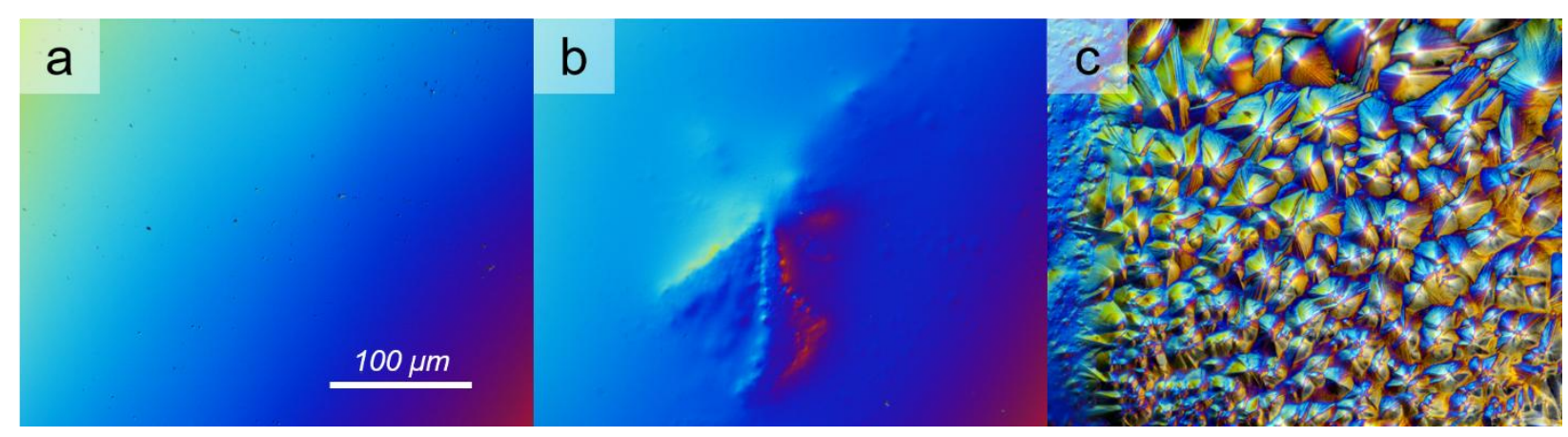

Figure 3 Differential interference contrast (DIC) optical micrographs showing the surface topography of various microstructures in the as-deposited libraries. a, Fully amorphous. b, Semi-crystalline. c, Crystalline.

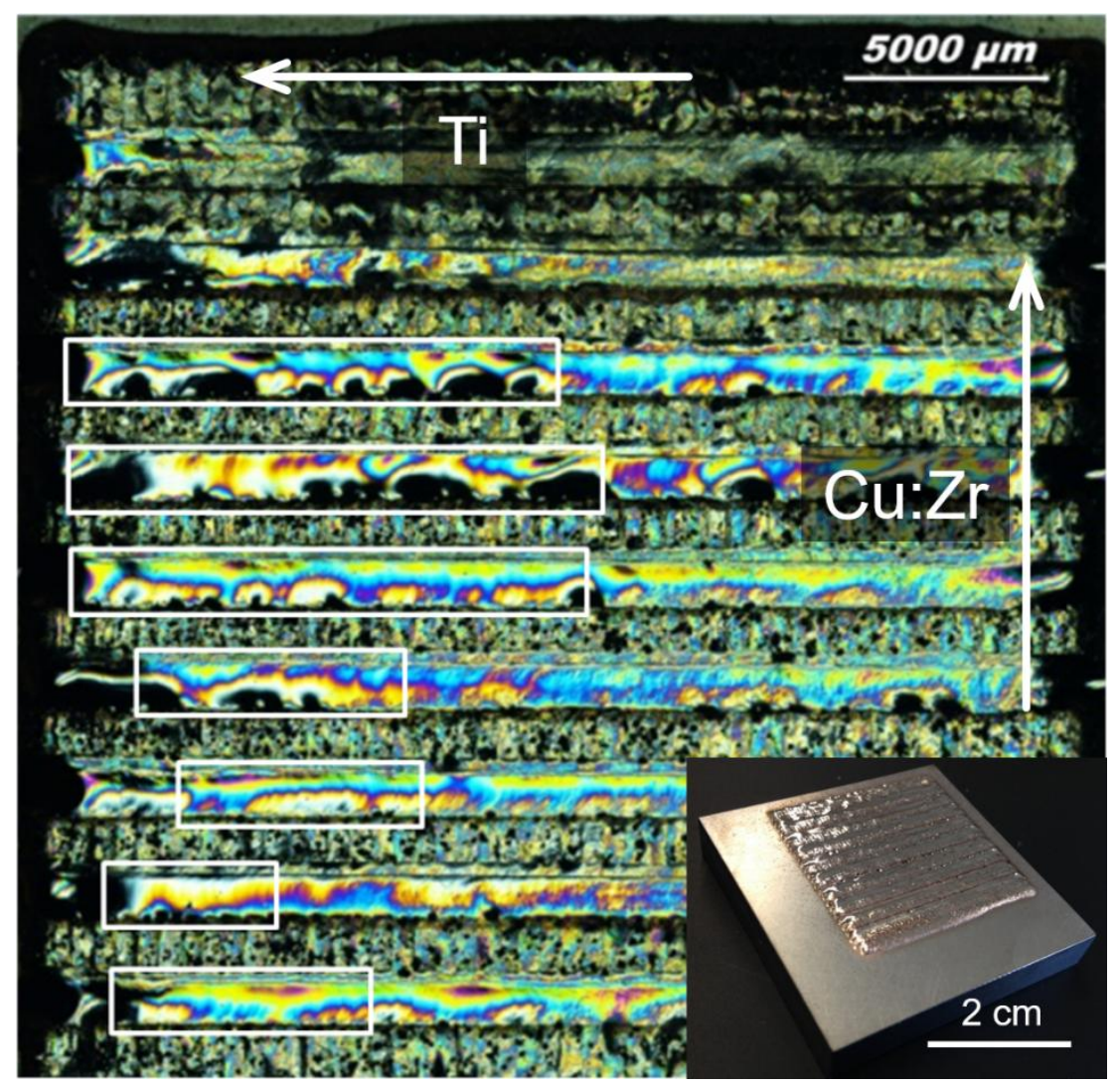

Figure $\mathbf{4}$ DIC image of the composition library processed with a $200 \mathrm{~W}$ laser. The boxed segments collectively represents the glass-forming region identified by observing the smooth, liquid-like topography of amorphous material. White arrows indicate directions of increasing $\mathrm{Ti}$ and $\mathrm{Cu}: \mathrm{Zr}$ molar ratio. Inset is a photograph of a complete as-deposited library. 


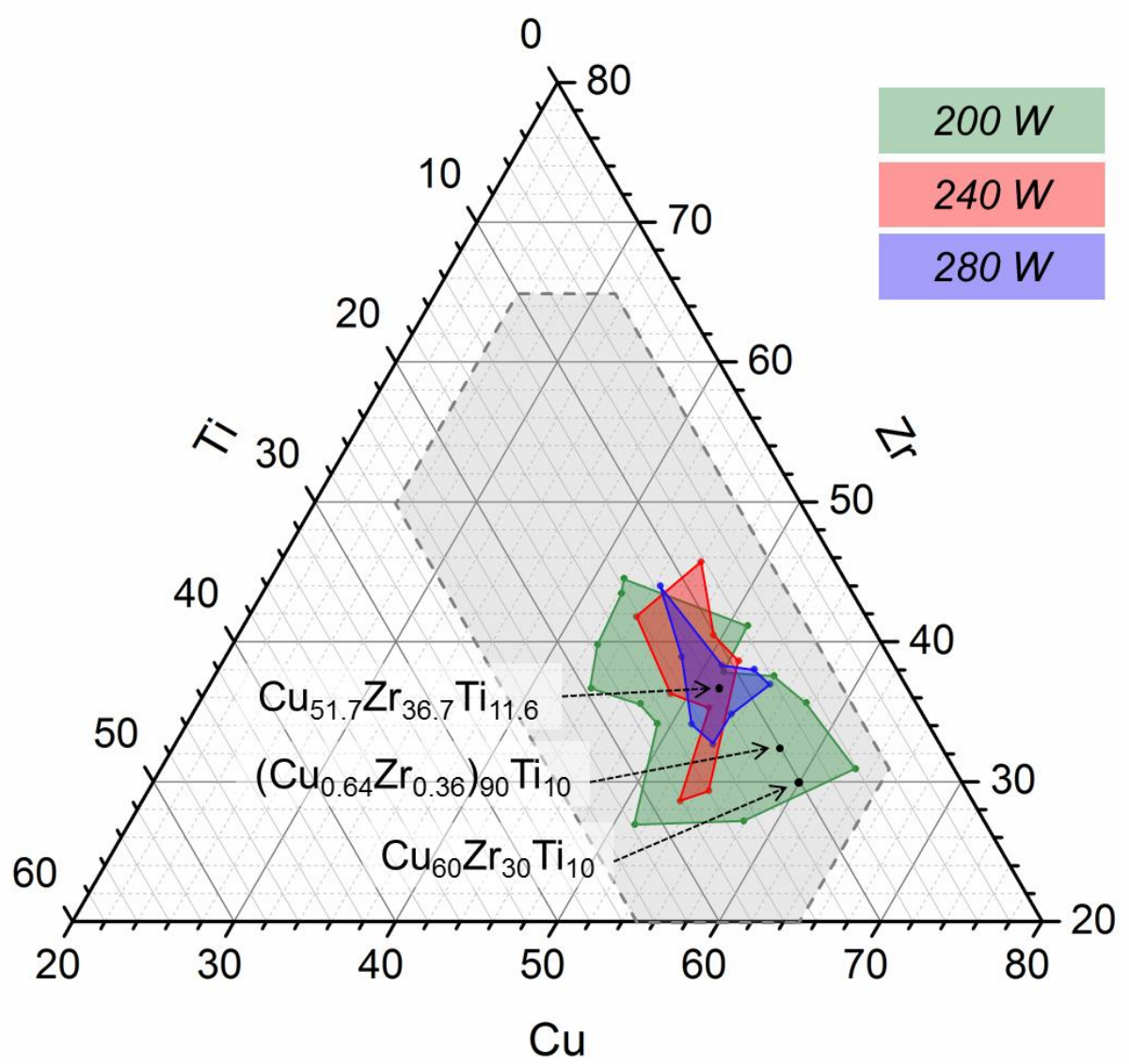

Figure 5 Vitrified regions of three composition libraries processed with different finalglazing laser powers $(200,240$, and $280 \mathrm{~W})$, plotted on a ternary composition map. The black dot within the glass region of the $280 \mathrm{~W}$ library is the predicted best glass former. The other two black dots are notable glass formers previously reported in other studies (Ref. 21, 36).The gray region approximates the overall extent of the ternary composition space contained within the three libraries. 


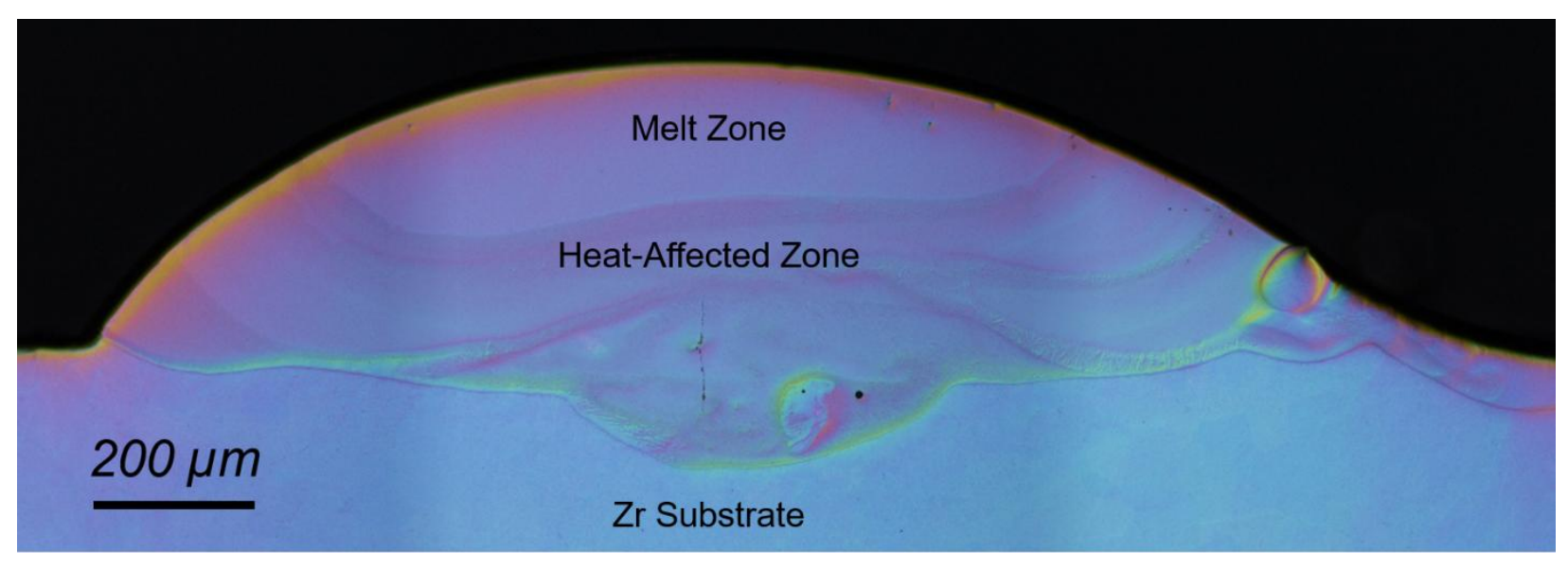

Figure 6 DIC image of a cross section through one of the dots screened as amorphous in the discrete composition library. Heat affected zones produced by the re-melting steps are visible surrounding a featureless melt zone. 

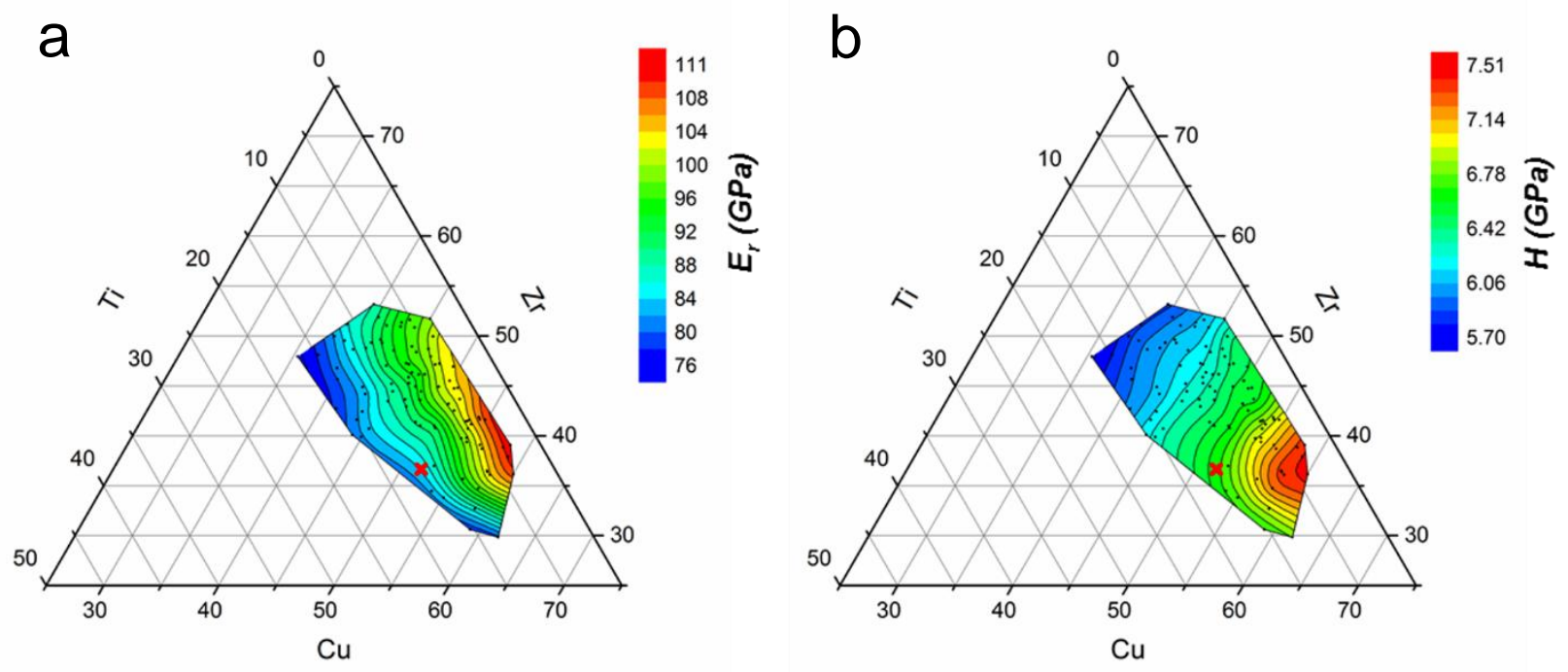

C

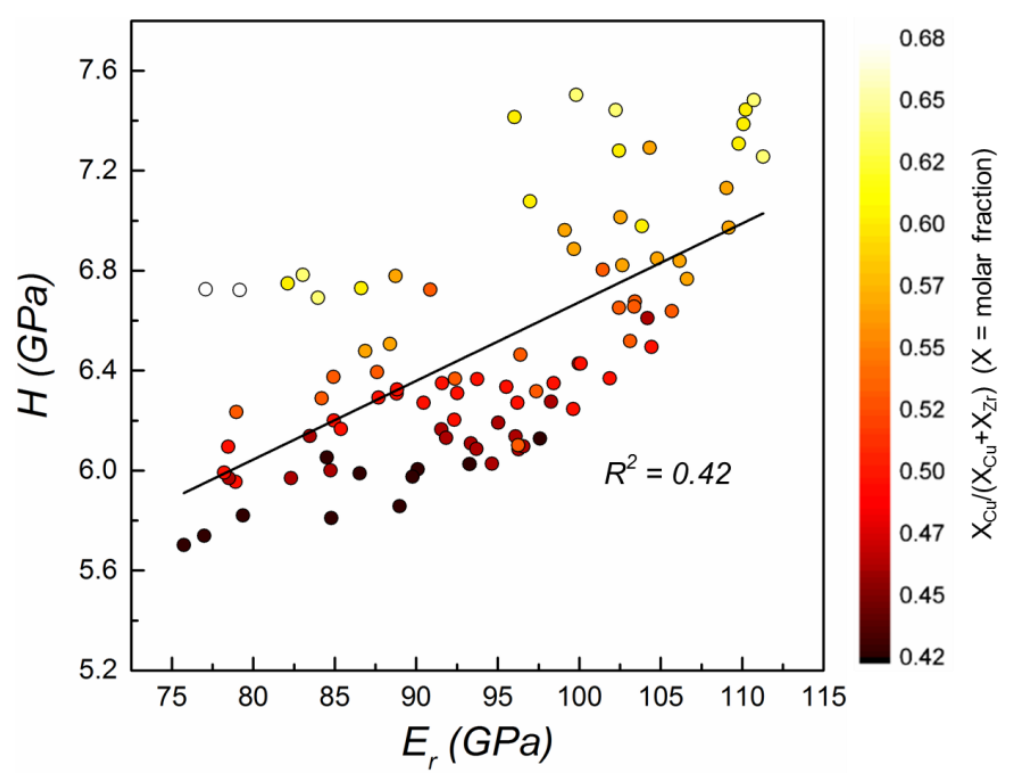

Figure 7 a, Reduced modulus and $\mathbf{b}$, hardness contour plots, constructed from nanoindentation measurements performed on 92 glassy alloys within the ternary Cu-ZrTi system. Our predicted best glass-former is indicated by a red X. c, Hardness plotted against the reduced modulus for all 92 alloys. The color of each data point indicates its corresponding $\mathrm{Cu}: \mathrm{Zr}$ molar ratio. 


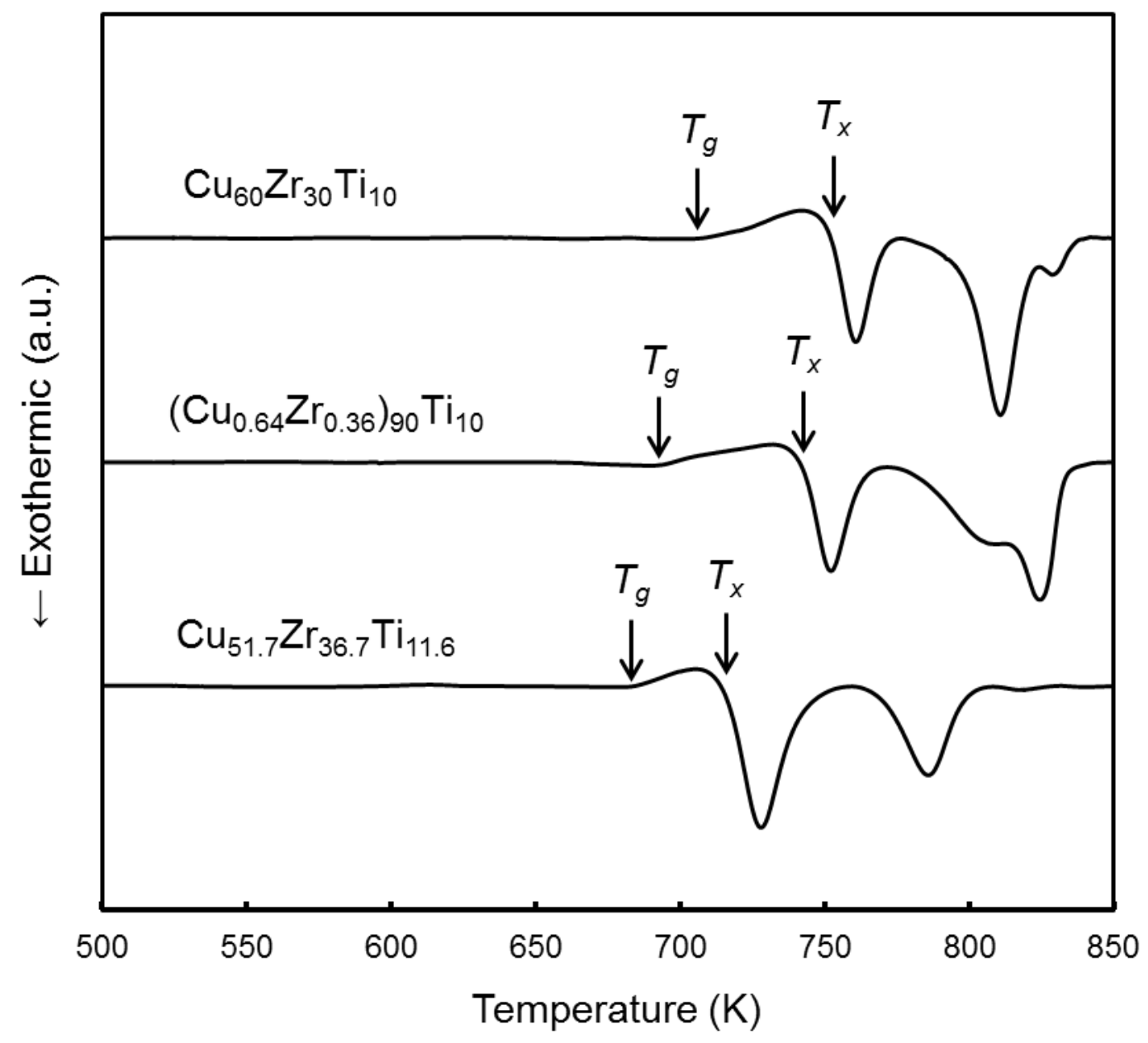

Figure 8 Differential scanning calorimetry heating traces of three suction-cast $\mathrm{Cu}-\mathrm{Zr}-\mathrm{Ti}$ metallic glass alloys. The scans were performed at a heating rate of $20 \mathrm{~K} / \mathrm{min}$. 
Table 1 Processing parameters for the $\mathrm{Cu}-\mathrm{Zr}$-Ti composition libraries.

\begin{tabular}{lcccccc}
\hline Library & \multicolumn{2}{c}{ Powder delivery rate $(\mathrm{g} / \mathrm{min})$} & $\begin{array}{c}\text { Laser travel speed } \\
(\mathrm{mm} / \mathrm{s})\end{array}$ & $\begin{array}{c}\text { Final re-melt } \\
\text { laser power }(\mathrm{W})\end{array}$ & $\begin{array}{c}\text { Average surface cooling } \\
\text { rate, } 1600-2200{ }^{\circ} \mathrm{C}\end{array}$ \\
\cline { 2 - 4 } & $\mathrm{Cu}$ & $\mathrm{Zr}$ & $\mathrm{Ti}$ & & & $(\mathrm{K} / \mathrm{s})$ \\
\hline Continuous 1 & 4.12 & 2.83 & 0.93 & $8.47-29.63$ & 200 & $1.68 \times 10^{4}$ \\
Continuous 2 & 4.12 & 2.83 & 1.3 & $8.47-29.63$ & 240 & $1.43 \times 10^{4}$ \\
Continuous 3 & 4.12 & 2.83 & 1.51 & $8.47-29.63$ & 280 & $1.19 \times 10^{4}$ \\
Discrete Array & $0.56-8.80$ & $2.51-0.77$ & 0.56 & $8.47-29.63(\mathrm{Ti})$ & 180 & - \\
\hline
\end{tabular}

Table 2 Characteristic temperatures, temperature-based predictive parameters, and wedge critical casting thickness $\left(d_{c}\right)$ of three Cu-Zr-Ti metallic glass alloys.

\begin{tabular}{lcccccc}
\hline Alloy Composition & $T_{g}(\mathrm{~K})$ & $T_{X}(\mathrm{~K})$ & $T_{l}(\mathrm{~K})$ & $T_{r g}$ & $\Delta T(\mathrm{~K})$ & $d_{c}(\mathrm{~mm})$ \\
\hline $\mathrm{Cu}_{60} \mathrm{Zr}_{30} \mathrm{Ti}_{10}$ & 708 & 751 & 1146 & 0.62 & 43 & 1.20 \\
$\left(\mathrm{Cu}_{0.64} \mathrm{Zr}_{0.36}\right)_{90} \mathrm{Ti}_{10}$ & 693 & 740 & 1167 & 0.59 & 47 & 1.35 \\
$\mathrm{Cu}_{51.7} \mathrm{Zr}_{36.7} \mathrm{Ti}_{11.6}$ & 682 & 715 & 1146 & 0.60 & 33 & 1.50 \\
\hline
\end{tabular}



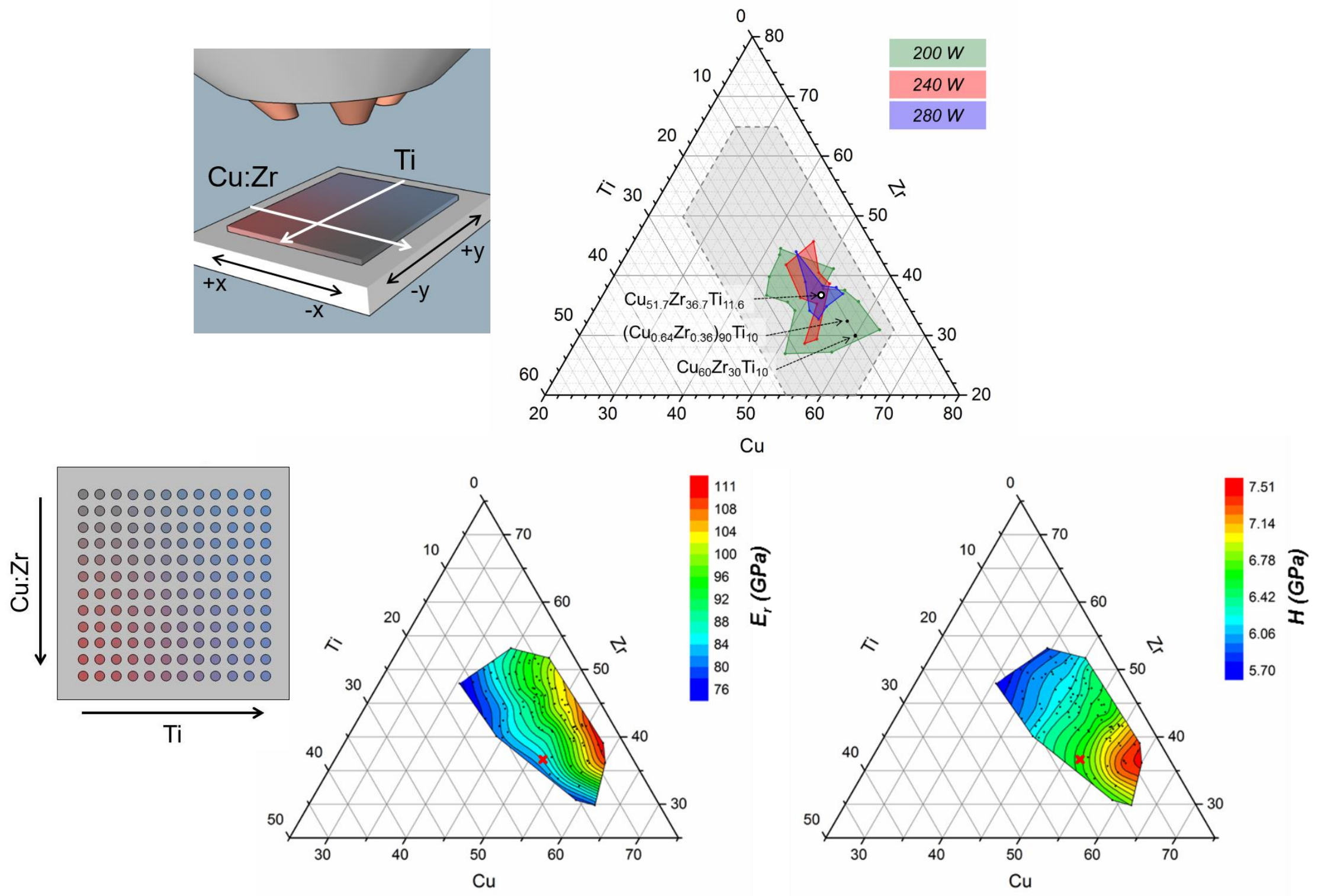